\title{
Promoting Political Empowerment: Evaluation of an Intervention With University Students ${ }^{1}$
}

\section{Holly Lizotte Angelique ${ }^{2}$}

The Pennsylvania State University, Capital College

\author{
Thomas M. Reischl \\ University of Michigan
}

\section{William S. Davidson II}

Michigan State University

\begin{abstract}
The aim of this research is to examine the effects of an intervention, focusing on the development of political empowerment, with university students. Undergraduates were randomly assigned to one of two conditions (intervention/ control) and were surveyed at two time points: before implementation of the intervention and upon completion of the intervention (or the equivalent two semester period). ANCOVA analyses reveal that individuals who participated in the empowering intervention had increased feelings of political commitment and a decreased sense of political efficacy compared to individuals who were randomly assigned to a waiting list/control group. Finally, limitations of this study are discussed and suggestions for future research are presented.
\end{abstract}

KEY WORDS: empowerment; political empowerment; efficacy; activism.

\footnotetext{
${ }^{1}$ We thank three anonymous reviewers for their helpful comments on earlier drafts of this paper. The data presented in this study are part of a larger data set collected for the first author's dissertation.

${ }^{2}$ To whom correspondence should be addressed at School of Behavioral Sciences and Education, Penn State, Harrisburg, Middletown, Pennsylvania 17057; e-mail: hxa11@psu.edu.
} 


\section{INTRODUCTION}

Can university courses promote the political empowerment of students? Some research has addressed the process of becoming politically empowered (Keiffer, 1984; Shields, 1992; Yeich, 1992), yet little is known about ways to promote its development. Political empowerment appears to be rooted in a commitment for social justice (Hirsch, 1990), social action (Maton \& Salem, 1995; Perkins \& Zimmerman, 1995; Zimmerman, 1995) and community involvement (Rappaport, 1981). Furthermore, empowerment appears to include an increased sense of efficacy (Fawcett et al., 1995; Hobfoll, 1998; Marín, Tschann, Gómez, \& Gregorich, 1998; Perkins \& Zimmerman, 1995; Zimmerman, 1995).

A task for community psychologists is to determine how to foster the development of political empowerment (Kelly, 1986; Perkins, Brown, \& Taylor, 1996; Stokols, 1986). Some research has attempted to document the process of political empowerment through self-report and retrospective data (Keiffer, 1984). Other research has attempted to identify predictors of community participation (Perkins et al., 1996). Although the process of becoming politically empowered has been previously addressed (Hermann, 1986), little is understood about the effects of deliberate attempts to promote empowerment in a sample of unempowered but earnest individuals. For community psychologists interested in structural change and fostering empowerment, this matter demands further exploration.

This paper explores the promotion of political empowerment in university students. It begins by defining political empowerment and then continues with an overview of political empowerment in psychological research. The characteristics of empowering settings is explained to provide a context for viewing the university classroom as a potentially empowering setting.

\section{Empowerment Terminology}

Gutierrez and Ortega (1991) have provided a useful tri-part typology of empowerment, including Personal Empowerment, Interpersonal Empowerment, and Political Empowerment. "Personal" empowerment is focused on ways to develop feelings of personal power and self efficacy. "Interpersonal" empowerment emphasizes the development of different skills, including helping people to help others and learning how to influence the political process (Beck, 1983; Gutierrez \& Ortega, 1991; Mathis \& Richan, 1986). "Political" empowerment stresses the goals of social action and social change. Political empowerment includes the intent to transfer power between groups of society, while maintaining that individual change is important (Fagan, 
1979; Kahn \& Bender, 1985; Longres \& McLeod, 1980). Similarly, political efficacy is the feeling that individual action can have an impact on the political process (Campbell, Gurin, \& Miller, 1954; Pollock, 1982; Stewart \& Weinstein, 1997). It should be noted that some concepts of empowerment, such as "actions" and "skill development" are process-oriented, whereas others, such as "efficacy" may be regarded as an outcome of empowerment. Some would argue that all forms of empowerment are situated in a sociopolitical context, and are thus, political by definition. To ensure accuracy, this paper will use the term Political Empowerment to denote the political nature of empowerment, and to focus on both the process and goal-orientation of its components. Many of these components are highlighted in psychological research.

\section{Themes of Political Empowerment in Research}

One recurring theme in political empowerment research is a commitment to act for social change (Donnelly \& Majka, 1998; Fyson, 1999). Although the process of empowerment may be complex and dynamic (FosterFishman \& Keys, 1997; Foster-Fishman, Salem, Chibnall, Legler, \& Yapchai, 1998; Zimmerman, 1990a; Zimmerman et al., 1992), Keiffer (1984) identified four distinct phases of development in grassroots activists, including eras of entry, advancement, incorporation, and commitment. Activists were initially politically alienated, but advanced with mentoring and increased critical awareness to incorporate their political beliefs and work into their personal lives. During the era of commitment, personal relationships changed and political action increased. Other researchers have found similar patterns of development. For example, Cross $(1971,1978)$ and Downing and Roush (1985) created models of Black Identity development and Feminist Identity development, respectively. Each model incorporated virtually identical stages, developing from a state of passivity into one of long term commitment.

Political empowerment is also linked to involvement in one's community (Heller, Price, Reinhartz, Riger, \& Wandersman, 1984; Perkins et al., 1996; Zimmerman,1990b), political actions (Stewart, Settles, \& Winter, 1998; Zimmerman, 1989), and feelings of efficacy (Cole, Zucker, \& Ostrove, 1998; Florin \& Wandersman, 1984; Hinkle, Fox-Cardamone, Haseleu, Brown, \& Irwin, 1996; Zimmerman \& Rappaport, 1988). In studies with college students and community residents, Zimmerman and Rappaport (1988) found that individuals with the highest community involvement had the highest empowerment scores. Similarly, efficacy offers an antidote to alienation and can be understood as a form of political powerfulness (Zimmerman, 1989). As such, efficacy may be a predictor of activism (Wittig, 1996). In short, characteristics of political empowerment include a commitment to a social 
cause, community involvement, and political efficacy. Some research has indicated that these characteristics may be fostered by creating empowering settings (Maton, 1993; Maton \& Salem, 1995).

\section{Characteristics of Empowering Environments}

Five main characteristics associated with empowering environments include small group settings (Bennett, 1992; Perry, 1968; Rose \& Black, 1985; Rappaport, 1987, 1990), a common belief system (Bargad \& Hyde, 1991; Cross, 1971, 1978; Downing \& Roush, 1985; Maton, 1993), opportunities to acquire skills and knowledge (Keiffer, 1984; Spreitzer, 1995), leadership (Bargad \& Hyde, 1991; Keiffer, 1984), and experience (Breton, 1990). Experience is based on the idea that one must spend a great deal of time in any given community to understand the people and the social problems of that community (Levine \& Levine, 1970; Levine \& Perkins, 1997; Malekoff, 1994). Freire $(1970 ; 1973)$ proposed an "emancipatory pedagogy" for empowering people and creating social change. A goal of emancipatory pedagogy is to become aware of the connections between personal experiences. This experiential education can be viewed as a tool of liberation by creating critical awareness about society, oppression, and history (Freire, 1970; Freire \& Macedo, 1987; Shor \& Freire, 1987; Stanage, 1986). These combined characteristics may promote the development of political empowerment over time. Furthermore, some settings (e.g., universities) are ideally structured for the creation of empowering environments.

\section{The University as an Empowering Setting}

Although some have critiqued contemporary university structures as being oppressive mechanisms of particular ideologies (e.g. Altback, Arnove, \& Kelly, 1982; Giroux \& Purpel, 1983; Levin, 1981), one of the hallmarks of higher education is clearly academic freedom as well as intellectual development and evolving critical awareness. University settings can be structured to create empowering environments, particularly in classes with many opportunities to acquire skills and knowledge, as well as develop critical thinking skills. Teachers can offer both supportive and challenging leadership. Universities often have resources that are readily accessible. Organizing classes into small groups, basing a class around a common social cause, and structuring many opportunities for hands-on community experience are all reasonable possibilities for community researchers and educators. In sum, the university can provide an appropriate setting for creating an empowering environment and investigating the development of political empowerment over time. 


\section{Rationale and Goals of This Study}

The current research examines the extent to which a university course, structured to be an empowering setting, can influence the development of political empowerment among students. This research question was pursued using an experimental study of a field-based course that introduced students to the juvenile justice system and provided students with opportunities to work as advocates and change agents with juvenile offenders for 18 weeks. This exploratory study was guided by the hypothesis that students completing a course with politically empowering characteristics will have increased levels of Political Commitment, Political Action, Community Involvement, and Political Efficacy, compared with students assigned to a waiting list. These dependent variables were selected based upon the literature reviewed.

\section{METHOD}

\section{Setting}

The setting for this research was a two-semester class offered through the psychology department of a large midwestern university. The student population is very diverse, including a large international community. The research took place within the context of an ongoing project that prepares student volunteers to work as advocates and behavioral trainers with juvenile offenders in the local community. The project (see Davidson, 1976; Davidson et al., 1977; Davidson \& Rapp, 1976; Davidson \& Rappaport, 1977; Eby et al., 1995; Mackin et al., 1995; Seidman, Rappaport \& Davidson, 1976a, 1976b; Shillo \& Davidson, 1994), operating since 1977, aims to divert adolescent youth away from the juvenile justice system by matching adolescents who have encountered the criminal justice system with university students.

\section{Research Participants}

Participants $(N=106)$ were undergraduate students who attended two orientation meetings for a two-semester fieldwork course, Psychological Innovation and Research. The prerequisites for this course included being a social science major in good academic standing and completing an introductory psychology course. Demographic characteristics of the participants are illustrated in Table I. Compared to the demographic characteristics of the university, this sample had a greater percentage of White students. All demographic information was self-reported, including descriptions of political 
Table I. Demographic Characteristics of Sample

\begin{tabular}{lcc}
\hline & Frequency & Percentage \\
\hline Gender & & \\
Male & 37 & 34.9 \\
Female & 69 & 65.1 \\
Age & & \\
$\quad<20$ & 28 & 26 \\
$20-24$ & 73 & 69.2 \\
$25-29$ & 4 & 00.4 \\
30+ & 1 & 00.9 \\
Race & & \\
African/African American & 1 & 00.9 \\
Asian/Asian American & 3 & 02.9 \\
Latina/Latino & 0 & 00 \\
Mixed race & 2 & 01.9 \\
White/Caucasian & 96 & 90.5 \\
Other & 4 & 03.8 \\
Political affiliation & & \\
Republican & 23 & 21.4 \\
Independent & 46 & 43.7 \\
Democrat & 24 & 22.3 \\
$\quad$ Undecided & 13 & 12.6 \\
Political ideology & & \\
Liberal & & \\
Moderate & 28 & 26.7 \\
Conservative & 46 & 43.8 \\
Not sure & 10 & 09.5 \\
\hline & 22 & 00.2 \\
\hline
\end{tabular}

affiliation and political ideology. No attempt was made to define these concepts for the participants.

\section{Research Design}

Respondents were randomly assigned to either participate in the intervention (Experimental Condition) or be placed on a waiting list (Control Condition). The effectiveness of the intervention was assessed by a singlefactor design (Experimental or Control Condition) at two time intervals (pre and post).

\section{Procedure}

\section{Administering the Pretest}

Although attending an orientation meeting about the course and the study, interested students signed informed consent forms and completed a 
survey with all the demographic and pretest measures. Immediately following this meeting, the students were randomly assigned to the intervention group (participating in the course) or to a wait list control group. Sixty-one students were assigned to the intervention/experimental group and 65 were assigned to the wait list/control group.

\section{The Intervention}

The intervention began with 14 weeks of classroom training, including weekly reading assignments and quizzes. It differed from traditional college courses in that the student/leader ratio was approximately 3/1. Training focused on learning behavior modification skills, providing community advocacy and understanding social problems related to adolescents. Students practiced effective behavior modification skills and advocacy via a series of role-playing exercises. After the classroom training, an experiential component (e.g., working one-on-one with a juvenile legal offender in the community) was the focus of the remainder of the intervention. At this point, students met in small groups (about six students) with a pair of leaders.

The course met the five criteria for an empowering setting. First, the intervention included commitment to a shared belief system. The common concern and shared goal was a desire to work toward eliminating juvenile delinquency. This project operated from a perspective that viewed juvenile delinquency as a social problem with both environmental and behavioral root causes. As such, the project aimed to train volunteers to intervene at both individual and societal levels (see Davidson \& Rappaport, 1978). At the individual level, behavior modification is the primary mode of intervention. At the societal level, advocacy is the primary model of intervention.

Second, the intervention met the criteria for an empowering setting through fostering small group interaction. The small group setting allowed for student and leader interactions. During the first weeks of training, groups of about 20 students assembled for about $1 \mathrm{hr} /$ week. Immediately following a large group discussion and small quiz, the groups broke down into groups of six for the remaining $1.5 \mathrm{hr}$ for more indepth discussion with two leaders. At week 6 of this 36-week project, individual groups of six students and two leaders were formed. These groups continued to meet weekly for $2.5 \mathrm{hr}$.

Third, leadership was deemed important. Leaders included graduate teaching assistants in community psychology as well as undergraduate supervisors who had previously completed the two-semester sequence. Leaders were selected by the professor for the course. They were selected, in part, for their varied backgrounds in community involvement, and they were trained in behavior modification and community advocacy intervention. The leaders 
used their own personal research and activism experiences as the groundwork from which to teach and advocate on behalf of the myriad of social issues that were faced. The backgrounds of the leaders at the time of this research included woman-battering, girls and delinquency, AIDS prevention, poverty, low-income housing problems, and school to work transitions. Leaders used critical discussions and their own activism as a tool for increasing political awareness.

Fourth, there were opportunities to acquire skills and knowledge, both in the classroom and in the community. The leaders provided classroom instruction and practice in the development of skills, including behavior modification and community advocacy. To increase knowledge about social problems as they pertain to adolescents, readings and discussions about social issues including delinquency, poverty, family violence, substance abuse, rape, incest, reproductive rights, legal rights, health care, employment and housing discrimination, and illiteracy were woven throughout the course. Readings by McIntosh (1989), Steele (1992), and Ryan (1976), on racial discrimination and victim blaming, respectively, were studied and discussed. ${ }^{3}$

Fifth, the format of classroom training gradually shifted to include more experiential learning. Once the classroom training had been successfully completed, each university student was assigned a court-referred youth to work with for an 18-week period. Adolescents and university students (under the supervision of the leaders) worked together to reach individually tailored goals, for at least 6-8 hr per week. During this fieldwork component of the class, undergraduates worked with families and within the community of their assigned youth. By working closely with the youth's family, the undergraduate could assist in setting up behavioral agreements that were appropriate to the needs of family members. In addition to working closely with family members, undergraduates worked with other community organizations, as needed. By becoming immersed in the community, the undergraduate could work effectively with the youth to secure access to local resources. The targeted areas for intervention included family, school, employment, and recreation. Additional areas were targeted on an individual-need basis (e.g., drug use, pregnancy, health problems, etc.).

\section{Posttest: Intervention Group}

Upon completion of the two-semester fieldwork course, all participants in the Experimental group were administered the survey again on the final day of class $(N=54)$. The attrition rate $(N=7 ; 11 \%)$ was due to 4 students

\footnotetext{
${ }^{3}$ The complete manual used during the intervention can be obtained by contacting the first
} author. 
who dropped the class (as well as the study), 1 who failed the class (and dropped out of the study), and 2 who completed the class but chose not to complete the study. Again, participants were informed that survey completion was completely voluntary and the information provided would remain confidential. Again, participants were asked to sign an informed consent form. Participants were thanked for their involvement.

\section{Posttest: Control Group}

All participants in the Control condition $(N=65)$ were invited to reconvene and complete a similar questionnaire. First, students in the control condition were sent a letter inviting them to attend a scheduled meeting, where they were administered a survey and received $\$ 10.00$.

Follow up phone calls were made to Control Group participants who did not respond to the first invitation, offering to schedule individual meetings at their convenience. They were contacted by phone (through information submitted during the course orientation and through the university's student directory), and invited to fill out a second questionnaire at their convenience, for which they would be paid $\$ 10.00$. Additional tracking methods (including letters and phone calls) to find participants through alternate contact persons were used as necessary, when participants were difficult to locate. The tracking procedures were moderately successful and most participants in the control group $(N=52 ; 80 \%)$ returned to complete a second survey. No significant differences were found between attriters and participants.

All pre- and posttests took about 20-30 min to complete. There were no significant differences between experimental and control groups. All participants were given the primary researcher's address to request study results.

\section{Measures}

Four measures were used to assess changes associated with political empowerment. Measures of political action, political commitment, political efficacy, and community involvement were used. Additionally, demographic information was collected. Following is a description of the measures used in this study.

\section{Political Action}

A seven item checklist of political actions comprised the Political Action Scale, one measure of Political Activism. This scale was adapted 
from Zimmerman (1989). This measure included a checklist of activities, including "Voting," "Participating in a boycott," and "Attending a political march." Respondents indicated whether they had participated in these activities within the last year. A summed score of all 10 items was determined, with higher scores reflecting more types of political actions. The reliability for the seven item scale was established for the present sample $(\alpha=.59)$.

\section{Political Commitment}

The measure of Political Commitment included statements such as "I have a lifelong commitment to work for social, economic, and political equality for all." Participants indicated the extent of their agreement with these statements on a 5-point (strongly agree-strongly disagree) Likert scale. The average rating agreement was determined for the six items comprising this scale. This measure was scaled such that the higher scores reflect higher levels of political commitment. The reliability for the resulting six-item scale was established for this sample $(\alpha=.69)$.

\section{Political Efficacy}

Six items from a scale constructed to measure political efficacy (Craig \& Maggiotto, 1982) were administered. This measure was designed to assess the extent to which one believes oneself to have the skills necessary to influence the political system. This nine-item scale included statements that represent internal political efficacy, or "individual's self-perceptions that they are capable of understanding politics and competent enough to participate in political acts such as voting" (Miller, Miller, \& Schneider, 1980, p. 253). Responses were in the form of a 5-point (strongly agree-strongly disagree) Likert format. The reliability for the resulting six item scale was established $(\alpha=.65)$. This measure was scaled such that the higher scores reflect higher internal political efficacy.

\section{Community Involvement}

Participants were asked to indicate the number of organizations and various communities they were involved in by responding to a seven item checklist including communities such as "Neighborhood," "Family," and "School." Additionally, respondents had the opportunity to list other organizations and communities that they were involved in. A summed score of all items was 
Table II. Means and Standard Deviations for Measures of Political Empowerment at Pretest and Posttest by Condition

\begin{tabular}{lcclcc}
\hline & \multicolumn{2}{c}{$\begin{array}{c}\text { Intervention group } \\
(n=54)\end{array}$} & & \multicolumn{2}{c}{$\begin{array}{c}\text { Control group } \\
(n=52)\end{array}$} \\
\cline { 2 - 3 } \cline { 6 - 7 } \multicolumn{1}{c}{ Subscales } & Pretest & Posttest & & Pretest & Posttest \\
& $M(S D)$ & $M(S D)$ & & $M(S D)$ & $M(S D)$ \\
\hline Political Efficacy & $3.15(0.60)$ & $3.06(0.57)$ & & $3.34(0.59)$ & $3.40(0.68)$ \\
Political Action & $1.72(1.46)$ & $1.48(1.34)$ & & $1.48(1.21)$ & $1.40(1.18)$ \\
Political Commitment & $2.93(0.67)$ & $3.15(0.72)$ & & $2.82(0.74)$ & $2.81(0.75)$ \\
Community Involvement & $1.09(1.20)$ & $0.93(1.18)$ & & $0.71(0.87)$ & $0.83(0.88)$ \\
Social Service & $4.18(0.89)$ & $4.09(0.80)$ & & $4.13(0.77)$ & $3.80(0.97)$ \\
\hline
\end{tabular}

Note. Standard deviations are reported in parentheses.

determined, with higher scores reflecting more types of community influences. In this sample, the reliability was established $(\alpha=.63)$.

\section{RESULTS}

Multivariate analysis of covariance (MANCOVA) was conducted to examine the effects of condition (class participation or college as usual) from Time 1 to Time 2. The MANCOVA revealed significant between group differences on political empowerment variables (Wilks' $\lambda=.28$ ), approximately $F(5,98)=8.06, p=.00$. This was followed by a series of univariate ANCOVA analyses to test the effects of condition on each of the five dependent variables at Time 2, using each of the five Time 1 scores as the covariates. For this study, ANCOVA was considered a more powerful test than repeated measures ANOVA, in that Main Effects could be tested, rather than Interaction (Time $\times$ Condition) Effects. Simply stated, ANCOVA was the more direct test. ANCOVA was used to directly test comparisons of two Time 2 scores, based on a Time 1 score.

Table II reports means and standard deviations for all measures at pretest and posttest, by condition. Table III reports the intercorrelations

Table III. Intercorrelations Between Political Efficacy, Political Action, Political Commitment, and Community Involvement Scales at Time 1 and Time 2

\begin{tabular}{lcccc}
\hline & 1. & 2. & 3. & 4. \\
\hline 1. Political Efficacy & 1.00 & $.20^{*}$ & $.30^{* *}$ & .03 \\
2. Political Action & $.21^{*}$ & 1.00 & $.24^{* *}$ & .14 \\
3. Political Commitment & $.33^{* *}$ & $.38^{* *}$ & 1.00 & .05 \\
4. Community Involvement & -.01 & $.23^{*}$ & $.22^{*}$ & 1.00 \\
\hline
\end{tabular}

Note. Time 1 correlations are depicted in the lower diagonal of the matrix. Time 2 correlations are depicted in the upper diagonal of the matrix.

${ }^{*} p<.05 .{ }^{* *} p<.01$. 
Table IV. ANCOVA Analyses

\begin{tabular}{lrcc}
\hline \multicolumn{1}{c}{ Source } & $d f$ & $F$ & $p$ \\
\hline Analysis of covariance for political action & & & \\
$\quad$ Condition & 1 & 0.04 & .84 \\
Pretest measure covariate & 1 & 40.89 & .00 \\
$S$ within-group error & 103 & $(1.15)$ & \\
Analysis of covariance for political commitment & & & \\
$\quad$ Condition & 1 & $4.81^{*}$ & .03 \\
Pretest measure covariate & 1 & 26.98 & .00 \\
$\quad$ within-group error & 102 & $(0.43)$ & \\
Analysis of covariance for political efficacy & & & \\
$\quad$ Condition & 1 & $5.35^{*}$ & .02 \\
Pretest measure covariate & 1 & 83.26 & .00 \\
$S$ within-group error & 103 & $(0.22)$ & \\
Analysis of covariance for community involvement & & & \\
$\quad$ Condition & 1 & 0.19 & .67 \\
Pretest measure covariate & 1 & 29.36 & .00 \\
$S$ within-group error & 103 & $(0.86)$ & \\
\hline
\end{tabular}

Note. Values enclosed in parentheses represent mean square errors; $S=$ subjects. ${ }^{*} p<.05$.

between the measures at Time 1 and Time 2. As illustrated, measures of Political Action, Political Commitment and Political Efficacy are significantly correlated at both Time 1 and Time 2. Community Involvement was correlated with Political Action and Political Commitment at Time 1 but not at Time 2.

ANCOVA analyses revealed that the intervention did have a significant effect on Political Commitment $F(1,1)=4.81, p<.05$, with a small effect size estimated $\left(\eta^{2}=.21\right)$. Intervention effects on Political Efficacy were significant, but in the opposite direction than was hypothesized $F(1,1)=5.35$, $p<.05$, with a medium effect size estimated $\left(\eta^{2}=.45\right)$. In other words, the intervention group scored lower on Political Efficacy at Time 2 than the control group. See Table IV.

In sum, evidence was found indicating that individuals randomly assigned to participate in the intervention had increased levels of Political Commitment compared to individuals who did not participate. In contrast, those who participated had decreased levels of Political Efficacy upon completion of the intervention compared to those who did not participate. No significant differences were found between participants and nonparticipants for Political Action or Community Involvement.

\section{DISCUSSION}

As hypothesized, the intervention caused increased feelings of political commitment. This finding was in accordance with Keiffer (1984) and others 
(Bargad \& Hyde, 1991; Cross, 1971, 1978; Downing \& Roush, 1985; Hirsch, 1990), further supporting a developmental model of political empowerment. However, contrary to expectation, this study did not find increases in activism nor in community involvement. It is possible that the intervention, with its requirements to spend a great deal of time in the community doing advocacy work, along with other fieldwork demands, may have become a substitute for other activism and community involvement. Another explanation is that the intervention may simply not have been strong enough to spark these behaviors. Perhaps this finding may be related to the decreases found in Political Efficacy.

One of the most interesting findings in this research was the intervention's apparent negative effect on Political Efficacy. This was contrary to the effect that was expected and contradicted past research findings as well (Cole et al., 1998; Florin \& Wandersman, 1984; Hinkle et al., 1996; Zimmerman, 1989; Zimmerman \& Rappaport, 1988). It may be that this was a fluke finding that could not be expected to be replicated. In this case, it may be discarded. However, it is also possible (as the empirical evaluation suggested) that the intervention effects were accurate and that certain "empowering" intervention $d o$ cause decreases in political competence and efficacy, at least in the short term. This possibility would warrant further discussion about the potential complexities of the role of Political Efficacy in the development of Political Empowerment.

A decrease in Political Efficacy may be a temporary state or a permanent trait. A temporary state of decreased Political Efficacy may be the result of being overwhelmed by the magnitude of the social problems that an individual encounters upon initially working for a cause that seems important to him or her. The basic humanitarian efforts that initially drove the community involvement may give way to a sense that the problems are too large to handle. Perhaps if this lack of efficacy is not consuming and the person is able to continue working for their social cause, a renewed, stronger sense of competence and efficacy will develop over time. If a temporary lag in political efficacy is common, an important intervention opportunity is presented. Depending upon how this developmental "transition point" is resolved, individuals may be inclined to "drop out" of their political activities if they become overwhelmed, while they may be prompted to "become immersed" in their activities as they recognize the need for action over time. Longitudinal research would be necessary to examine this interpretation.

However, this decrease in Political Efficacy may be a permanent trait, at least for some individuals. Interpreting the decrease in Political Efficacy as a temporary state is an optimistic perspective. Students may be driven by idealized notions of activist work. The reality of the difficult, often unrewarding day to day work may be overwhelming. This lack of immediate 
gratification and potential for limited, if any, long term results may be a learning experience for many. Although their commitment to work for a cause might remain high, their feelings of efficacy may subside.

\section{Limitations of This Study}

One limitation of this study concerns the independent variable, the empowering intervention. This intervention included many different components, including small group size, mentors and leaders, skill development, access to resources, and immersion in the community. However, these domains were not evaluated separately but were instead combined in one intervention effort. The results indicated that an intervention with all of the aforementioned components can lead to increased political commitment. However, this research is limited in that the main effects of each component of the intervention and interaction effects cannot be ascertained. Although it is important to discover which mechanisms are effective in triggering the development of political empowerment, this research has only tapped into one general approach.

Another limitation was the relatively short time interim, which spanned only 36 weeks. It should be noted that the development of political empowerment may extend over longer periods of time. On the other hand, this course did require an extensive time commitment from its participants. Therefore, students who wanted to enroll for this course typically did not have many outside obligations, such as full time jobs, families, etc. The course typically attracted economically privileged psychology students, from more affluent hometowns, most of whom were female and White. In contrast, most of the juvenile offenders were from less affluent areas of the inner city. They were predominantly male and predominantly of ethnic minority status. Results may have varied tremendously with pairs matched by gender, ethnic/racial background, and economic class. As such, the process of political empowerment may have been obstructed by race, class and gender divisions. Perhaps with more diversity within the student population, more indepth "emancipatory" education (Freire, 1970) for both the research participants as well as the juveniles from the local community would have been possible.

There are ecological challenges associated with an intervention that utilizes both university and community settings. To set up this type of intervention requires university support. The high student/teacher assistant ratio requires a great deal of funding. There must be more interest in participation than the course can accommodate in order for random assignment to be feasible and ethical. The intervention included individually tailored experiences and took place in many different family, school, and community 
settings. Accordingly, mundane realism is high, but replication would be a challenge.

Finally, it is important to note the low alphas of some of the measures. They simply may not have been accurate measures of some of the dependent variables. Perhaps measuring these constructs of political empowerment with other indicators would reveal different findings. Along these lines, these measures were not validated on other samples. We must acknowledge that this study was essentially exploratory. It was an investigation with one university class, during one particular time period, participating in one very specific type of empowerment program.

\section{Implications for Future Research}

Although this study indicated that an empowering intervention can promote the development of Political Commitment, the most salient aspects of the intervention remain unknown. Future experiments should consider the evaluation of different levels of the intervention. For example, one group may participate in small group settings with a leader, whereas another group may participate in small group settings without an assigned leader. In this way, it might be possible to distinguish between the effects of small group participation and having a leader on the development of political empowerment. In this way, the most important triggers of the empowerment process may be identified.

This study should also be replicated in similar settings, as well as in different environments. Furthermore, the potential reciprocal influence between the adolescents in the community and the university students should be explored in greater detail in future investigations. For example, this study described how working with an adolescent can be a very empowering experience for an undergraduate student. However, this study did not explore the extent to which working with an undergraduate student can be a very empowering experience for an adolescent. Nor did this study investigate the ways in which continued relationships between undergraduate students and community youths can be mutually beneficial. Adolescents can offer important perspectives based on their lived experience and undergraduates can offer important perspectives based on their knowledge and training. The reciprocal influences that the undergraduates and the adolescents might offer each other was overlooked in this research. With further analyses of these dynamic processes we can begin to understand the mechanisms by which empowerment can be fostered in the community in addition to the impact of community involvement on university students.

There may be many different paths to political empowerment. Quantitative data and experimental designs are useful to establish causal relationships, 
eliminate extraneous variables, and to test group differences. However, quantitative analyses can mask different patterns of experiences that may be meaningful for a complete understanding of the process of political empowerment. In future research, supplementing experiments with qualitative analyses could add richness and texture to research findings from quantitative analyses. More importantly, qualitative analyses could help to reveal specific mechanisms that trigger the development of empowerment.

This study suggested that it is possible for university based courses to be designed to inspire some aspects of political empowerment to develop. The results of sparking political empowerment may not be immediate. Undergraduate students may not finish a course and proceed to the nearest political event. However, with a new sense of political commitment, undergraduates could become increasingly more politically empowered and active over time.

\section{REFERENCES}

Alltback, P., Arnove, R., \& Kelly, G. (1982). Comparative education. New York: MacMillan. Bargad, A., \& Hyde, J. S. (1991). A study of feminist identity development in women. Psychology of Women Quarterly, 15, 188-201.

Beck, B. (1983). Empowerment: A future goal of social work (Working Papers in Social Policy). New York: CSS.

Bennett, E. M. (1992). Community-based economic development: A strategy for primary prevention. Canadian Journal of Community Mental Health, 11, 11-33.

Breton, M. (1990). Learning from social group work traditions. Social Work with Groups, 13(3), 21-34.

Campbell, A., Gurin, G., \& Miller, W. E. (1954). The voter decides. Evanston, IL: Harper \& Row.

Cole, E. R., Zucker, A. N., \& Ostrove, J. M. (1998). Political participation and feminist consciousness among women activists of the 1960's. Political Psychology, 19(2), 349-371.

Craig, S. C., \& Maggiotto, M. A. (1982). Measuring political efficacy. Political Methodology, 8, 85-109.

Cross, W. E. (1971). Negro-to-black conversion experience: Toward a psychology of black liberation. Black World, 20, 13-27.

Cross, W. E. (1978). The thomas and cross models of psychological nigrescence: A review. Journal of Black Psychology, 5, 13-31.

Davidson, W. S. (1976). The diversion of juvenile delinquents: An explanation of the processes and relative efficacy of child advocacy and behavioral contracting. Unpublished doctoral dissertation, University of Illinois at Urbana-Champagne.

Davidson, W. S., \& Rapp, C. (1976). Child advocacy in the justice system. Social Work, 21, $225-232$.

Davidson, W. S., \& Rappaport, J. (1977). Toward a model for advocacy: Values, roles, and conceptions from community psychology. In G. Weber \& G. McCall (Eds.), Advocacy in the disciplines. New York: Sage.

Davidson, W. S., \& Rappaport, J. (1978). Toward a model for advocacy: Values, roles, and conceptions form community psychology. In G. H. Weber \& G. J. McCall (Eds.), Social scientists as advocates: Views from applied disciplines. Beverly Hills, CA: Sage.

Davidson, W. S., Seidman, E. S., Rappaport, J., Berck, P. L., Rapp, C., Rhodes W., et al. (1977). Diversion program for juvenile offenders. Social Work Research and Abstracts, 1, 40-54. 
Donnelly, P. G., \& Majka, T. J. (1998). Residents' efforts at neighborhood stabilization: Facing the challenges of inner-city neighborhoods. Sociological Forum, 13(2), 189-213.

Downing, N., \& Roush, K. (1985). From passive acceptance to active commitment: A model of feminist identity development for women. The Counseling Psychologist, 13, 695709 .

Eby, K. K., Mackin, J. R., Scofield, M. G., Legler, R. E., \& Davidson, W. S. (1995). The adolescent diversion project. In R. R. Ross, D. H. Antonowicz, \& G. K. Dhaliwal (Eds.), Going straight: Effective delinquency prevention and offender rehabilitation (pp 79-108). Ottawa, Canada: Air Training \& Publications.

Fagan, H. (1979). Empowerment skills for parish social action. New York: Paulist Press.

Fawcett, S. B., Paine-Andrews, A., Francisco, V. T., Schultz, J. A., Richter, K. P., Lewis, R. K., et al. (1995). Using empowerment theory in collaborative partnerships for community health and development. American Journal of Community Psychology, 23(5), 677 697.

Florin, P., \& Wandersman, A. (1984). Cognitive social learning and participation in community development. American Journal of Community Psychology, 12, 689-708.

Foster-Fishman, P. G., \& Keys, C. B. (1997). The person/environment dynamics of employee empowerment: An organizational culture analysis. American Journal of Community Psychology, 25(3), 345-369.

Foster-Fishman, P. G., Salem, D., Chibnall, S., Legler, R., \& Yapchai, C. (1998). Empirical support for the critical assumptions of empowerment theory. American Journal of Community Psychology, 26(4), 507-536.

Freire, P. (1970). Pedagogy of the oppressed. New York: Seabury Press.

Freire, P. (1973). Education for critical consciousness. New York: Seabury Press.

Freire, P., \& Macedo, D. (1987). Literacy: Reading the word and the world. Massachusetts: Bergin \& Garvey.

Fyson, S. J. (1999). Developing and applying concepts about community: Reflections from the field. Journal of Community Psychology, 27(3), 347-365.

Giroux, H., \& Purpel, D. (Eds.). (1983). The hidden curriculum and moral education: Deception or discovery. Berkley, CA: McCutchan.

Gutierrez, L. M., \& Ortega, R. (1991). Developing methods to empower latinos: The importance of groups. Social Work with Groups, 14(2), 23-43.

Heller, K., Price, R. H., Reinhartz, S., Riger, S., \& Wasserman, A. (1984). Psychology and community change: Challenges of the future (2nd ed.). Homewood, IL: Dorsey.

Hermann, M. (1986). Political psychology. San Francisco, CA: Jossey Bass.

Hinkle, S., Fox-Cardamone, L., Haseleu, J. A., Brown, R., \& Irwin, L. (1996). Grassroots political action as an intergroup phenomenon. Journal of Social Issues, 52(1), 39-51.

Hirsch, E. L. (1990). Sacrifice for the cause: Group processes, recruitment, and commitment in a student social movement. American Sociological Review, 55, 243-254.

Hobfoll, S. E. (1998). Ecology, community and adis prevention. American Journal of Community Psychology, 26(1), 133-144.

Kahn, A., \& Bender, E. (1985). Self help groups as a crucible for people empowerment in the context of social development. Social Development Issues, 9, 4-13.

Keiffer, C. (1984). Citizen empowerment: A developmental perspective. Prevention in Human Services, 3(2-3), 9-36.

Kelly, J. G. (1986). Context and process: An ecological view of the interdependence of practice and research. American Journal of Community Psychology, 14, 581-589.

Levin, H. (1981). The identity crisis of education planning. Harvard Educational Review, 51(1), 85-93.

Levine, M., \& Levine, A. (1970). A social history of helping services: Clinic, court, school and community. New York: Appleton-Century-Crofts.

Levine, M., \& Perkins, D. (1997). Principles of community psychology: Perspectives and applications (2nd ed). New York: Oxford University Press.

Longress, J., \& McLeod, E. (1980). Consciousness raising and social work. Social Casework, 61, 267-276. 
Mackin, J. R., Eby, K. K., Scofield, M. G., \& Davidson, W. S. (1995). Integrating the ivory tower and the community: The adolescent diversion project. In J. P. McKinney, L. B. Shiamburg, $\&$ L. Shelton (Eds.), Teaching the course on adolescent development. New York: Garland Press.

Malekoff, A. (1994). Action research: An approach to preventing substance abuse and promoting social competency. Health and Social Work, 19(1), 46-53.

Marín, B. V., Tschann, J. M., Gómez, C. A., \& Gregorich, S. (1998). Self-efficacy to use condoms in unmarried latino adults. American Journal of Community Psychology, 26(1), 53-72.

Mathis, T., \& Richan, D. (1986). Empowerment: Practice in search of a theory. Paper presented at the Annual Program Meeting of the Council on Social Work. Miami, FL: Education.

Maton, K. I. (1993). The biennial conference: A foundation of empowerment? The Community Psychologist, 27, 29-31.

Maton, K. I., \& Salem, D. A. (1995). Organizational characteristics of empowering community settings: A multiple case study approach. American Journal of Community Psychology, 23(5), 631-656.

McIntosh, P. (1989, July/August). White privilege: Unpacking the invisible knapsack. Peace and Freedom, 10-12.

Miller, W. E., Miller, A. H., \& Schneidner, E. J. (1980). American national election studies sourcebook: 1952-1978. Cambridge, MA: Harvard University Press.

Perkins, D. D., Brown, B. B., \& Taylor, R. B. (1996). The ecology of empowerment: Predicting participation in community organizations. Journal of Social Issues, 52(1), 85-110.

Perkins, D. D., \& Zimmerman, M. A. (1995). Empowerment theory, research, and application. American Journal of Community Psychology, 23(5), 569-579.

Perry, W. (1968). Forms of intellectual and ethical development in the college years, New York: Holt, Rinehart \& Winston.

Pollock, P. H. (1982). Organizations and alienation: The meditation hypothesis revisited. The Sociological Quarterly, 23, 143-155.

Rappaport, J. (1981). In praise of paradox: A social policy of empowerment over prevention. American Journal of Community Psychology, 9, 1-25.

Rappaport, J. (1987). Terms of empowerment/exemplars of prevention: Toward a theory for community psychology. American Journal of Community Psychology, 15, 121-148.

Rappaport, J. (1990). Research methods and the empowerment social agenda. In P. Tolan, C. Keys, F. Chertok, \& L. Jason (Eds.), Researching Community Psychology (pp. 51-63). Washington, DC: American Psychological Association.

Rose, S., \& Black, B. (1985). Advocacy and empowerment: Mental health care in the community. Boston: Routledge \& Kegan Paul.

Ryan, W. (1976). Blaming the victim. New York: Vintage Books.

Seidman, E. S., Rappaport, J., \& Davidson, W. S. (1976a). Adolescence in legal jeopardy: Initial success and replication of an alternative to the criminal justice system. Invited Address: 1976 National Psychological Consultants to Management Consulting Psychology Research Award. Meeting of the American Psychological Association, Washington, DC.

Seidman, E. S., Rappaport, J., \& Davidson, W. S. (1976b). Diversion programs for juvenile offenders. Consulting Psychologists, 21, 13-16.

Shields, L. E. (1992). The development of a model of empowerment with women: Implications for health planning and practice. Unpublished doctoral dissertation, University of Oregon.

Shillo, B. A., \& Davidson, W. S. (1994). Alternatives to secure detention for juvenille offenders: The case of diversion. Journal for Juvenile Justice and Detention Services, 9(Spring), 7-16.

Shor, I., \& Freire, P. (1987). A pedagogy for liberation: Dialogues on transforming education. Massachusetts: Bergin \& Garvey.

Spreitzer, G. M. (1995). An empirical test of a comprehensive model of intrapersonal empowerment in the workplace. American Journal of Community Psychology, 23(5), 601-629.

Stanage, S. M. (1986). "Unrestraining" liberty: Adult education and the empowerment of persons. Adult Education Quarterly, 36, 123-129.

Steele, C. (1992, July/August). Race and the schooling of black americans. The Atlantic Monthly, 68-78. 
Stewart, A. J., Settles, I. H., \& Winter, N. J. G. (1998). Women and the social movements of the 1960's: Activists, engaged observers, and nonparticipants. Political Psychology, 19(1), 63-94.

Stewart, E., \& Weinstein, R. S. (1997). Volunteer participation in context: Motivations and political efficacy within three aids organizations. American Journal of Community Psychology, 25(6), 809-838.

Stokols, D. (1986). The research psychologist as social change agent. American Journal of Community Psychology, 14(6), 595-599.

Wittig, M. A. (1996). An introduction to social psychological perspectives in grassroots organizing. Journal of Social Issues, 52(1), 3-14.

Yeich, S. (1992). Empowerment and structural change: The creation of a homeless person's union. Unpublished doctoral dissertation, Michigan State University, E. Lansing.

Zimmerman, M. A. (1989). The relationship between political efficacy and citizen participation: Construct validation studies. Journal of Personality Assessment, 53(3), 554-566.

Zimmerman, M. A. (1990a). Taking aim on empowerment research: On the distinction between individual and psychological conceptions. American Journal of Community Psychology, 18(1), 169-177.

Zimmerman, M. A. (1990b). Toward a theory of learned hopefulness: A structural model analysis of participation and empowerment. Journal of Research in Personality, 24, 7186.

Zimmerman, M. A. (1995). Psychological empowerment: Issues and illustrations. American Journal of Community Psychology, 23(5), 581-599.

Zimmerman, M. A., Israel, B. A., Schulz, A., \& Checkoway, B. (1992). Further explorations of empowerment theory: An empirical analysis of psychological empowerment. American Journal of Community Psychology, 20, 707-728.

Zimmerman, M. A., \& Rappaport, J. (1988). Citizen participation, perceived control, and psychological empowerment. American Journal of Community Psychology, 16, 725-750. 